\title{
"Ya no la lira de Orfeo sino el qhirqhinchu del layqa": la concepción de la muerte en el mundo andino en Rosa Cuchillo de Óscar Colchado Lucio y El pez de oro de Gamaliel Churata
}

Matías Di Benedetto

\begin{abstract}
Resumen
Este texto analiza dos de las obras más importantes de la literatura peruana moderna a partir de la revisión de la categoría de muerte en el mundo andino. Nos interesa poner en relación tanto en El pez de oro de Gamaliel Churata como en Rosa Cuchillo de Óscar Colchado Lucio la particular concepción del espacio cosmológico destinado a los muertos y su específica relación con una idea de la Historia entendida ya no como progreso sino más bien como recuperación de un pasado en constante tensión con el presente. Veremos así cómo ambas textualidades buscan una reivindicación de los saberes locales, así como también formas alternativas de organización de un sujeto colectivo arraigado al territorio.
\end{abstract}

PALABRAS CLAVE: Muerte, Historia, espacio, Churata, Colchado

No longer Orpheus' lyre but the qhirqhinchu of layga: the conception of death in the Andean world in Rosa Cuchillo by Oscar Colchado Lucio and in El pez de oro by Gamaliel Churata

\begin{abstract}
This text analyzes two of the most important works of modern Peruvian literature from the viewpoint of the concept of death in the Andean world. We thus review Gamaliel Churata's El pez de oro and Oscar Colchado Lucio's Rosa Cuchillo with a focus on the particular conception of the cosmological space associated with the dead and its relationship with History, no longer understood as progress but rather as a recovery from a past in constant tension with the present. We will see how both texts seek a vindication of local knowledges and alternative forms of organization of a territory-specific collective subject.
\end{abstract}

KEYWORDS: Death, History, space, Churata, Colchado 


\section{"Não mais a lira de Orfeo, mas o qhirqhinchu do layqa": a concepção da morte no mundo andino em Rosa Cuchillo de Óscar Colchado Lucio e El pez de oro de Gamaliel Churata}

\section{Resumo}

Este texto analisa duas das obras mais importantes da literatura moderna peruana, a partir da revisão da categoria de morte no mundo andino. Estamos interessados em relacionar a concepção particular do espaço cosmológico destinado aos mortos e sua relação específica com uma idéia da história entendida não mais como progresso, mas como uma recuperação de um passado em constante tensão com o presente em El pez de oro, de Gamaliel Churata, e em Rosa Cuchillo, de Oscar Colchado Lucio. Veremos como ambas as textualidades buscam uma reivindicação do conhecimento local, bem como formas alternativas de organização de um sujeito coletivo enraizado no território.

PALAVRAS CHAVE: Morte, História, espaço, Churata, Colchado

\section{Una temporalidad enmarañada}

Este artículo tiene como objetivo la revisión de un tópico literario recurrente en la literatura occidental, aunque en este caso lo pondremos en relación con dos obras fundamentales de la literatura peruana moderna. Nos referimos a la espacialización y recorrido por el mundo de los muertos, tanto en el capítulo seis de El pez de oro de Gamaliel Churata, aparecido por primera vez en 1957, así como en Rosa Cuchillo de Óscar Colchado Lucio, publicado cuarenta años después, en 1997. En ambos puede decirse que, en primer lugar, se pone en juego una revalorización de la categoría de muerte en el mundo andino en conjunto con una relectura de la tradición literaria occidental, y en segundo lugar, se manifiesta la instalación, como núcleo de sentido, de una convergencia entre mito e Historia. Asimismo, cada uno de estos textos, mediante distintos mecanismos compositivos, fomenta una estructura narrativa que pone en crisis el tratamiento del referente indígena tal y como lo plantea el indigenismo literario, ${ }^{1}$ y reivindica una regionalización del proyecto estético de la Modernidad.

Esta adaptación de lo moderno adquiere visos de travesía en ambas narraciones. La retórica del viaje es el esquema estético utilizado para confrontar mito e Historia en el marco de estos proyectos escriturarios que buscan desmantelar la Modernidad desde (y para) Latinoamérica. Pero no solo los mitos prehispánicos van a ser parte de esta polarización sino también el mito occidental del progreso entendido como motor del devenir histórico. En el escenario cósmico conformado por las tres Pachas (Hanan Pacha, Kay Pacha, Ukhu Pacha) el tiempo mítico se instala en el tiempo histórico con el objetivo de renovarse a través de una regeneración continua del mundo, repitiendo los

\footnotetext{
1 Una descripción de esta particularidad la lleva a cabo con creces Antonio Cornejo Polar durante gran parte de su labor crítica. Define esta situación de desbalance entre el narrador y el mundo representado mediante la noción de exterioridad. Esta funciona como eje de la "heterogeneidad constitutiva" (1982: 93) de la narrativa indigenista ya que asume una posición central para la arquitectura de la obra literaria de temática indígena, pues da cuenta de su descalabro estructural. Se trata de "un suceso culturalmente heterogéneo en el que el referente pertenece a un universo y todos los demás factores a otro distinto y hasta opuesto" (2008: 45). Citamos, a modo de ejemplo, un pasaje del artículo "Aves sin nido: Indios, "notables' y forasteros" en el que Cornejo Polar carga las tintas acerca del concepto de exterioridad plasmado en la estructura misma de la novela de Clorinda Matto de Turner. Como muestra de la insistencia metodológica con que sostiene la operatividad de dicho término, Cornejo Polar escribe que "la condición necesaria de la novela indigenista es, precisamente, su exterioridad. La novela indigenista, como por lo demás todo el movimiento indigenista, es un hecho pluricultural y plurisocial que se distingue por producirse en un mundo que no es, precisamente, el mundo al que se refieren sus obras" (2008: 28).
} 
acontecimientos hasta que se produzca una restitución del Tahuantinsuyu en el presente. Ambas obras, en definitiva, van a exponer una "geografía de la utopía andina" (Flores Galindo, 1988: 92) de manera literal con la intención de, una vez delimitado el territorio, establecer una voz narrativa de rasgos propios. Un punto de vista capaz de exponer la continuidad entre el mundo de los vivos y los muertos que la noción de muerte andina sostiene en ambas estéticas escriturarias así como, en consecuencia, cristalizar una forma de mirar hacia el pasado en conexión directa con el presente.

Sin embargo, la clave histórica de ambas textualidades difiere en algunos aspectos. En la escritura de Churata, la torsión del abordaje historicista clásico, acumulativo en su forma de ver los acontecimientos, resuena incluso a nivel subjetivo. La fundamentación de su propia estética a partir de un componente autobiográfico ubica la propuesta narrativa de Churata en un lugar intermedio entre la escritura diarística y las reflexiones filosóficas, decisión literaria que conlleva una mirada original sobre el ordenamiento teleológico de los hechos. No por nada en El pez de oro puede observarse cómo se efectúa un relevamiento de los episodios de la propia biografía de Churata, ya que de lo que se trata es de llevar a cabo una operación de expansión de lo individual como pretensión general del proyecto creador churatiano. Esta práctica de lectura de lo íntimo como acto estrechamente ligado a la escritura adquiere además una novedosa significación si advertimos su funcionamiento en tanto que reinterpretación de la Historia. Respecto a este tema, llama la atención la manera en que las constantes reflexiones acerca de la muerte de su hijo Teófano en El pez de oro se vuelven el acervo subjetivo de una teorización acerca del modo en que debe funcionar el sustrato histórico de la ficción literaria.

Es que en esa resistencia a asimilar el hecho de la muerte de su hijo se percibe la definición no solo del sujeto andino en relación con sus antepasados sino también su propia concepción de la realidad y de la Historia. Al respecto, con posterioridad a la primera edición de El pez de oro en 1957, Churata ofrece una conferencia luego de su retorno de Bolivia, ${ }^{2}$ el 3 de enero de 1965, en el Cine Puno, titulada "El pez de oro, o dialéctica del realismo psíquico, alfabeto del incognoscible” ${ }^{3}$. Allí hace énfasis en la posibilidad de narrar la realidad y la Historia de manera no progresiva ni lineal. Para llevar adelante semejante tarea, Churata trae a colación esa idea referida a la permanencia de los muertos en el presente tal y como aparecía en "Trenos del chio

\footnotetext{
2 Envalentonado como consecuencia de su retorno a Perú luego del largo exilio en Bolivia, en esa conferencia Churata hace las veces de eximio comentador de un texto aparentemente trabajoso para el público lector. Anuncia, grandilocuente, el libro que vendrá. Hace públicas sus intenciones al dar cuenta de un proyecto creador que supera el horizonte estético instalado por El pez de oro. Dice: "Y agregar ahora que el volumen édito es solo el primero de otros que le siguen, y que completarán acaso una suerte de epopeya del Hombre Animal. En efecto, tras El pez de oro, debe aparecer Resurrección de los muertos [...] [allí] se acomete al análisis del problema dialéctico del ajayu watan [...]. Tras ese volumen viene otro, denominado Mayéutica, en poemas didascálicos, que ahonda el sentido del esquema. A Mayéutica habrá de seguir un diálogo, que he denominado Platón y el Puma [...] contra el idealismo espiritualista del socratismo platónico. Y ya le seguirán Qhirqhillas de la Sirena, poemario Titicaca, en abono del símbolo matriarcal de las aguas. Luego, Baladas, Jaylli Incásico, poemario de tono épico [...]. Tras esto vendrá otro de singular dramática, Los pueblo resucitan, sobre la base de la cinemática del ajayu watan. Y ya entramos a las Biorritmias del Tawantinsuyu [...]. Y allí cierra el periplo con la pieza Qosqo wara [...]" (2011: 56).

3 A principios de la década del treinta, luego de que el Boletín Titikaka dejara de publicarse, el gobierno del presidente Leguía llega a su fin con el golpe de Estado de Sánchez Cerro, el cual convierte en blanco de sus persecuciones políticas a Churata, motivadas al parecer por su cercanía al APRA y al Partido Comunista. El autor de El pez de oro decide viajar a Bolivia y establecerse en La Paz. Allí pasa los siguientes treinta y dos años y es donde paulatinamente se acrecienta su labor periodística en la mayoría de los periódicos del país: La Semana Gráfica, La Gaceta de Bolivia, La Calle, Ultima Hora, La Razón. Como consecuencia de su desempeño en los medios gráficos, y en compañía de Huayna Cápac Chuquiwanka, funda en 1939 el matutino El Expreso Matinal, el cual por una serie de problemas económicos debe declararse en quiebra. Sin embargo, el prestigio de Churata permanece incólume y se mantiene como jefe de redacción de Última Hora desde 1945 hasta 1950 aproximadamente. Allí, en Bolivia, es donde publica por primera vez El pez de oro en 1957.
} 
khori", un relato publicado en el Boletín Titikaka durante el mes de marzo de 1929. Al referirse al significado de El pez de or ${ }^{4}$ en dicha conferencia, Churata señala:

[...] ese libro se dirige a sustentar un conocimiento realista de los problemas anímicos humanos, y de las leyes de la historia, haciendo necesario comprender que la muerte es un mito, y que si la semilla del hombre no muere, y no muere su capacidad nemotécnica, su naturaleza de individuo histórico, hoy que hablo a ustedes, les habloy en mí hay prójimos nuestros que les hablan, como en ustedes hay conciencias lúcidas y honradas que al oírme entienden que la muerte fue creación del alma enferma del hombre [...]. Y si los hombres no mueren, los pueblos que son formación de hombres, tampoco pueden morir. (2012: 61, el énfasis es nuestro)

Como se observa, en la equiparación del realismo con las "leyes de la historia" ambas estructuras narrativas se ven interpeladas por la inversión del orden lógico que conlleva la centralidad de un concepto específico como es el de la muerte. ${ }^{5} \mathrm{~A}$ contramano del tratamiento de este tema por parte de las religiones occidentales, Churata socava sus postulados al reinterpretar sus conceptualizaciones mediante el uso de un término particular. La "nekrademia" es definida como el elenco de antepasados que arrastra cada sujeto consigo mismo, es decir, la permanencia de los muertos en la subjetividad de los vivos se da a través de su alojamiento en la conciencia. Por lo tanto, la redefinición de las formas de narrar la Historia a partir de una reconsideración de la noción de muerte tiene su correlato en el texto mismo de Churata, como veremos en el capítulo seis "Puro andar".

Asimismo, en Rosa Cuchillo encontramos en las primeras líneas de la novela a la protagonista del relato, Rosa Wanka, quien inicia su travesía luego de morir de pena a causa del asesinato de su hijo Liborio, militante senderista, a manos de las fuerzas represivas del Estado, mientras le pregunta a una voz anónima: “¿Por aquí? ¿Por estos lugares se irían los muertos?" (2005: 7). Dicha frase concentra dos aspectos importantes: se trata del núcleo cardinal a partir del cual, por un lado, se despliegan las secuencias narrativas así como, por otro lado, se expone la fuerte imbricación entre espacio y cosmovisión andina. En Rosa Cuchillo, coincidentemente, el tema del hijo fallecido sostiene todo el armazón del relato, impulsa, al fin y al cabo, desde el comienzo, la travesía. Rosa acaba de fallecer y desde ese grado cero del relato, ubicado en las alturas de Illaurocancha, un poblado de Ayacucho, revisa el pasado inmediato a su muerte en el mundo de los vivos, mientras va en busca del mundo superior en donde están las almas de los runas de buen comportamiento y la de su hijo Liborio.

La tragedia personal, específicamente la pérdida de un hijo, emerge como el catalizador de una búsqueda narrativa capaz de derruir una narrativa indigenista que tomaba distancia del referente. Tanto en El pez de oro como en Rosa Cuchillo la exploración del mundo de los muertos es funcional no solo a la construcción de una actualización mítica de la tan mentada utopía andina mediante la desconfiguración del tiempo acumulativo, sino que también propone un abigarramiento temporal (Rivera Cusicanqui, 2018), una

4 A propósito de esta cuestión, Aymará de Llano en su artículo "Sobre El pez de oro, o dialéctica del realismo síquico" enfatiza, en primer lugar, en la actividad de promotor cultural que llevó Churata al frente de la publicación del Boletín Titikaka, y cómo sus ideas "representan un momento clave en el debate indigenista". Pero el núcleo temático del texto gravita alrededor de la conferencia que brinda Churata cuando retorna a Perú luego de su exilio boliviano. La autora afirma que funciona como posible "metatexto explicativo de su controvertida novela vanguardista/ indigenista". De esta manera, de Llano desarma y expone los componentes de ese "artefacto de vanguardia que abreva en las matrices indígenas" (2009: 52). Recientemente, De Llano vuelve sobre esta conferencia en su artículo "Vivir será germinar. El pez de oro y la célula" con la intención de leer el sustrato biologicista de las argumentaciones de Churata a partir de la noción de célula en dicha conferencia.

5 Un desarrollo más profundo de este tema puede encontrarse en Di Benedetto, Matías, “Un muerto-vivo en las cumbres andinas: El pez de oro y el retorno de la vanguardia”, incluido en la compilación de artículos Churata desde el sur, a cargo de Dorian Espezúa y Nécker Salazar. 
temporalidad enmarañada entendida como punto de fuga de la maquinaria mimética y, por ende, de los emplazamientos subjetivos disponibles. Las ficciones que analizamos en este artículo promueven novedosas formas de cuajar lo histórico y lo político. Si, por ejemplo, en Rosa Cuchillo hallamos un reajuste cabal de los formatos narrativos abocados a la violencia política de los años ochenta y noventa en el Perú, en el capítulo "Puro andar" de El pez de oro se desafía no solo una tradición literaria ligada con la literatura occidental sino que también se hace mella en la desregulación de los vaivenes entre ficción y "metarrelatos políticos o programas colectivos" (García Canclini, 2010: 233) como sostén de una particular política de la literatura. ${ }^{6}$ Veamos a continuación de qué manera funcionan estas caracterizaciones de ambas obras en nuestro análisis.

\section{El infierno está encantador}

En el capítulo "Puro andar", el narrador inicia su recorrido por el mundo de abajo no sin antes detenerse "ante la puerta fantasmal", mientras desestima la famosa advertencia: "Lasciate ogni speranza / voi che entrate" [abandonen toda esperanza / aquellos que entren aquí] (2014: 564) que Dante Alighieri asoció con dicho acceso al Infierno en su Divina comedia. La intención manifiesta de este pasaje de la obra churatiana es la demolición de la imagen del infierno de tradición cristiana y occidental. Con ese fin, pone en funcionamiento un dispositivo narrativo confeccionado por dos operaciones complementarias. En primer lugar, el narrador hace foco, ubica en primer plano a esas figuras emparentadas con la muerte denominadas chullpas en la cosmovisión andina. ${ }^{7}$ En este sentido, y luego de traspasar el umbral del mundo de abajo, se observa una cualidad específica de este espacio de los muertos: su carencia de profundidad. Como era de esperarse, y este es quizás el motivo oculto de la falta de comentarios acerca de lo que se describe, el protagonista abandona cualquier atisbo de centralidad que lo vincule con prácticas escriturales propias de un extranjero atento a lo circundante desde su propia óptica cultural en analogía con, por ejemplo, uno de los viajeros europeos en tierras americanas. No hay aquí un discurso de la racionalidad que intente ordenar lo que se ve, desentrañar los motivos de las actividades infernales o bien dar cuenta de los accidentes geográficos del submundo del mismo modo que lo hacen Dante o Virgilio. El retablo suma, una tras otra, escenas colmadas de significaciones afines con la realidad andina para desarmar una concepción historicista ligada directamente con la noción de progreso. Se trata específicamente de una interrupción de la travesía infernal entendida como discurrir histórico mediante diferentes escenas, algunas de las cuales se tornan núcleos temáticos centrales para entender de otra manera la historia latinoamericana.

6 "Política de la literatura" es una expresión del filósofo francés Jacques Rancière que establece relaciones con otro de sus conceptos como lo es el de "divisiones de lo sensible". La "estética del desacuerdo" de Rancière, como la denomina el propio Néstor García Canclini en La sociedad sin relato, establece el punto nodal de su propuesta de análisis. Planteando la desestructuración de las "divisiones de lo sensible" que calan hondo en las formas de imaginar esquemas de pensamiento comunes, la estética política del filósofo francés articula una manera de observar la "visibilidad de lo escondido" y un reconocimiento de la potencialidad del disenso, el desacuerdo entre diferentes regímenes de sensorialidad. Por esta razón, lo que se busca es aplicar, poner en funcionamiento una concepción de la literatura y del arte en tanto que estimulación del disenso y no artefacto destinado al restablecimiento de convenciones sociales.

7 Esta categoría varía en su mención e incluso instala un campo semántico a lo largo del capítulo: chullpa (sepulcro), chullpa thullu (el esqueleto vivo), chullpar (cementerio), el chullpa (americano legendario de edades presolares) son algunas de sus apariciones más llamativas. Según Helena Usandizaga, estas expresiones “apuntan a las figuras de los muertos y a sus lugares como lección de vida e inmortalidad” ya que, mediante la relación entre vida y muerte como conceptos contrapuestos a través de la centralidad de la semilla, la muerte solo puede producir más vida. Es decir, el cementerio es un lugar de potencialidades estéticas: si "chullpa" se refiere a los individuos que vivían en el altiplano antes del diluvio, y cuyos restos se encuentran entre las ruinas y tumbas precolombinas, se trata más bien de ancestros tutelares, los cuales “impulsan el pasado hacia el futuro" (2005: 47). Es decir, se busca a fin de cuentas un proyecto histórico específico que actúe como base teórica de la estética germinal de Churata, un pasado indígena como pasado fecundador de futuro. 
A medida que se aventura en territorio de los muertos, el narrador churatiano apela a un procedimiento de desmantelamiento de los lugares comunes de la literatura canónica occidental. Por ejemplo, su viaje comienza con un reconocimiento de las fuentes mitológicas que resuenan en su descenso a ese mundo de abajo. Por eso allí están las referencias ineludibles a la mitología griega a través de una mención a Orfeo; alusiones transculturadas en función del acervo mitológico pre-hispánico. Orfeo adquiere, en consecuencia, rasgos de influencia pero también se asume como material del inminente proceso de reescritura, un claro gesto complementario a una estrategia de desmantelamiento de los repertorios culturales importados desde las metrópolis europeas. En relación con este tema, puede leerse en un pasaje del retablo: "Y bajé a los infiernos, bien que no pulsando la heptacorde, sino el quirqhuinchu del layqa" (2011:361). Ya no es la lira de Orfeo, entonces, lo que el narrador lleva consigo en su itinerario. Aquí se convierte en un charango, el charango del layga.

Es decir, al esgrimir un instrumento que le pertenece a esa figura, matriz fundamental de su proyecto estético como vemos ya desde el subtítulo "Retablos del Laykhakuy", el narrador churatiano se asoma a lo desconocido aunque sin dejar de tomar posición con respecto a los temas y motivos literarios que le van a servir de insumos. El espesor simbólico de lo helénico se desecha en función de una entronización de la cosmovisión andina que tiene como representante al layqa, una especie de brujo capaz de mantenerse en un lugar enunciativo entre ambos mundos, un entre lugar como punto de partida de una práctica escrituraria que le permite "elevar los valores del esqueleto humano a categorías estéticas" o como señala una voz narrativa que toma la palabra en un pasaje del retablo, "algo (disculpad si a tamaño ejemplo acudo) así como el Dante con la teología hizo en su inmortal poema" (2014: 612).

Esta superposición de espacios que tiene como epicentro al layqa se asienta, para su desarrollo textual, en el segundo gesto del dispositivo narrativo desplegado en este capítulo. Si el primero apunta a la particular descripción del entorno infernal, vaciada de detalles puntuales, en una segunda instancia se advierte una constante reflexión acerca del rol del sujeto de la historia. Ese montón de ruinas que el ángel de la historia deja detrás suyo, tal y como lo describe Walter Benjamin en Sobre el concepto de historia (2007), se vuelve no ya un ejemplo de la naturaleza catastrófica sobre la que se asienta la idea de progreso en la Historia, sino más bien un acervo testimonial. Para sostener el diagnóstico de un presente que se desmorona por influjo del pasado, el narrador que explora el mundo de los muertos recupera de ese conjunto de voces una potencia discursiva capaz de derruir lo historizado en función de la idea de progreso. De esta manera, la pervivencia de los muertos en el mundo de los vivos se presentifica mediante la inclusión de pasajes narrativos que funcionan a modo de pequeñas escenas a partir de las cuales se ponen en discusión problemáticas coyunturales de la realidad latinoamericana y que, además, sirven como interrupciones de la concepción lineal de la Historia que traza el narrador en su recorrido.

Por ejemplo, la vertical relación entre hacendados y pongos, que conforma un particular entramado en la sociedad andina, se visibiliza a través de una escena en particular:

[...] uno de los Chullpa Thullus, que se negaba a perder la memoria, porfiaba porque su siervo -indio, naturalmente- siguiérale prestando servicios gratuitos. Como el incoado se resistiera, se formaron bandos: unos que al amo, otros que al ciervo. Aquello era revolcón de hedores cívicos. (2012: 603)

El pongo, por su parte, responde haciendo alusión a Simón Bolívar y a Ramón Castilla, quienes abolieron el trabajo forzoso de los indígenas en el Perú. Esta escena, que nos recuerda al relato recogido y traducido por José María Arguedas titulado "El pongo" 
o que incluso se asemeja al relato "El gamonal" del propio Churata, se suma a otro momento significativo del retablo en el que el narrador se explaya acerca de un lugar común de la historia de nuestro continente y que se relaciona directamente con esta práctica explotadora antes mencionada.

El racismo, en consecuencia, aflora en otro pasaje del capítulo a partir de una reflexión que el narrador aporta al llegar a una "ciudadela de las cumbres de acero cruel" (2012: 597). Ahí mismo se describe dicho lugar: se trata de una "república de mulatos, lobos, cambujos, torna-atrases, albarizados, barainos, coyotes, tente-en-el-aires, no-te-entiendos... América, América: no te entendemos" (2012: 597). En tanto racionalización ideológica de la esclavitud así como operación fetichista que toma un rasgo, un elemento del otro y lo eleva a condición ontológica, estatuto del ser del otro, transformándolo en ese mismo proceso mientras se confunde la parte y el todo, el racismo opera como ideología de las estrategias de expoliación aplicadas sobre las poblaciones andinas desde la Conquista. La matriz lógica de la fetichización, nos dice el narrador con la inclusión de ambas escenas en su recorrido por el mundo de los muertos, tiene como condición histórica de posibilidad el modo de producción capitalista basado en la esclavitud. Y por ende, el racismo biologicista se vuelve un elemento presente en el escenario infernal: describe a las claras los significantes disponibles, tanto epocales como culturales, que forman parte del delirio clasificatorio que busca una jerarquía entre grupos humanos a partir de la emergencia de un concepto de raza como "organizador de las categorías de diferenciación" (Grüner, 2010: 140).

El tránsito por el espacio de los muertos se asienta discursivamente en una frase repetida cuya utilidad radica en la delimitación temática de cada una de las escenas así como también en la recuperación de una idea del territorio más bien problemática. La conformación de esta geografía del infierno constituye una lengua particular, una grafía en tanto que escritura del geos pensada a partir de un "Andar, andar" dicho una y otra vez por un narrador que expone, como estrategia literaria, el intento de hacerse cargo de una concepción de la Historia que se corre de las reflexiones occidentales. Asimismo, esta especie de ritornello subraya no solo un movimiento constante sino también una supeditación a determinados rasgos de la concepción espacio-temporal andina propia de los caminos, entendidos estos como terrenos de tránsito y a la vez fronterizos. Si en la cosmovisión andina las encrucijadas funcionan como ámbitos en donde se ponen en contacto los muertos y los vivos junto con todos los seres vivientes, llama la atención cómo estos muertos que andan "no dejan rastro por el mundo de los vivos" (Aguiluz Ibarguen, 2015: 228).

La persecución de esas figuraciones sin huella, Churata la lleva adelante desprendiéndose del lastre conceptual propio de las tradiciones de pensamiento occidentales. En un claro gesto de resistencia que se sostiene mediante una cartografía transformadora de los imaginarios colectivos, su "trabajo descolonizador" (Moraña, 2015: 218) dice más del rol que ocupan las multitudes y el tumulto que de la pluralización de lo premoderno en conjunto con los procesos modernizadores en Latinoamérica. En este sentido, puede leerse en un pasaje de "Puro andar":

Nunca escasearon las obras de pluma, pincel o escoplo, que se dedicaron a los muertos, veces para hacer fisga de ellos y de sus pobres huesos, veces para ensartarles elegías no menos onerosas. Lo que entendemos como historia del hombre: historia de su muerte. Por filosofía de sus valores, la filosofía de su subitaneidad. Por teología: llevarle a su implacable destino: la muerte [...]. ¿Es que habréis de admitir la realidad sólo si se os ofrece académicamente adobada? (2012: 617)

La universalidad otra gestionada desde una plataforma enunciativa de corte local que propone Churata se asume como coartada a la imposición academicista y, por 
ende, occidental, con que Colchado organiza su novela. A través de dicha narración se pone en funcionamiento una primigenia experiencia espacial conformada mediante un apego al territorio en tanto que convivencia del pasado y el presente que no desprestigia su articulación cosmológica. Se trata de una manera de estar en el lugar que adquiere particularidades más que llamativas en Rosa Cuchillo y que tiene en la reivindicación de los saberes andinos su principal interés.

\section{Lo portátil como resistencia}

Como ya señalamos al comienzo, la visión triádica del espacio-tiempo en la cosmovisión andina reviste la forma de una totalidad compleja, ambigua y multioperante, con fronteras lábiles que despliegan "una ubicuidad metaespacial y animista de las entidades que las pueblan" (Lozada, 1995: 472). Esas mismas fronteras endebles entre los tres espacios promueven una interacción organicista del mundo andino: todos los elementos de la naturaleza, incluido el hombre, forman un todo interrelacionado. Dicho aspecto, al contrario de lo esperado, no reduce la ficción de Colchado a un despliegue enciclopédico de figuras y creencias míticas de raigambre andina. Estas van a estar, claramente, pero intercaladas con un conjunto interesantísimo de procedimientos narrativos. Son, sin ir más lejos, los mecanismos compositivos que resuenan en la forma del relato mediante las focalizaciones narrativas desplegadas. Las voces, en consecuencia, se entremezclan, dialogan entre ellas, se refutan y se compenetran, tal y como sucede cuando Rosa llega al pantano de aguas heladas y le cede la narración a "un gran entrevero", un conjunto de voces conformado por senderistas, ronderos e infantes de Marina:

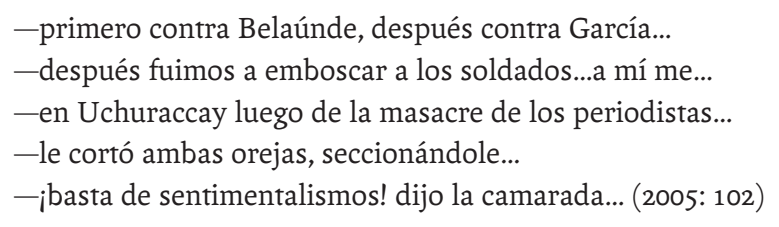

En esta puesta en abismo de lo que la novela de Colchado realiza a gran escala con los discursos contrapuestos de la racionalidad occidental (López Maguiña, 2005) y los esquemas de pensamiento andinos, se observa una marcada tendencia a poner en primer plano una noción de resistencia andina, cuyo efecto inmediato es la suspensión de un utópico diálogo entre culturas. Sin ir más lejos, las voces de estos sujetos representados en Rosa Cuchillo se muestran como agentes de la violencia desprovistos de distinción ideológica ya que, en conclusión, todos ellos desintegran la racionalidad mítica que ordena la comunidad andina: "Los senderistas y los miembros de las fuerzas represivas del Estado, actúan como desintegradores externos del mundo quechua, mientras que los ronderos, como agentes internos de dicha desintegración" (Pérez Orozco, 2011: 211).

La ficción de Colchado traza en paralelo un proceso de materialización del imaginario andino con la clara intención de ilustrar el Ukhu Pacha, su propia disposición y el elenco de seres mitológicos que lo habitan. A diferencia de lo buscado por Churata en "Puro andar", aquí Colchado profundiza el relevamiento de dicho espacio sin la mención de todo el aparato conceptual del imaginario católico o de las tradiciones literarias de Occidente. Es verdad que en el propio descenso al mundo de los muertos resulta innegable la influencia de los relatos al respecto propios de la literatura europea, sin embargo en Rosa Cuchillo se efectúa tanto un relevamiento minucioso de dicho escenario, como también se da lugar para una preponderancia de los códigos culturales propios del mundo andino, en detrimento de los consabidos presupuestos ideológicos de Occidente. 
Como punto de partida de los comentarios acerca de estos aspectos de la novela de Colchado, nos interesa poner el acento en el rol de waksha del personaje Rosa Wanka, quien desde una perspectiva narrativa autodiegética se adentra en el mundo de los muertos. La importancia de dicha categoría andina se debe a su capacidad para acentuar, en principio, el estado de marginalidad del que parte la protagonista: "En una sociedad cuya base es el colectivismo, el mantenerse o quedar al margen de ella es concebido como una condición extrema a la que puede ser relegado un individuo. Esto implica quedarse sin familia, sin comunidad, en el peor de los casos sin espacio y tierras, para convertirse en extraño extranjero" (González, 2002: 27). Por afuera de las relaciones establecidas de antemano y mientras asume rasgos de extrañeza, de alteridad capaz de distanciarse del flujo de la vida en comunidad, Rosa Wanka asume una condición extraterritorial (Steiner, 2009) que le permite, al fin y al cabo, arraigarse en la errancia. Su nomadismo por la triple espacialidad andina la lleva a pasar revista por una serie de figuras mitológicas presentes en cada uno de esos espacios, actividad móvil que se contrapone directamente a la carencia principal que esbozan los sujetos anclados en ese territorio.

Quienes más llaman la atención son los condenados, "aquellos que no han llevado a cabo la reciprocidad, la relacionalidad, las normas de parentesco con su comunidad" (Pérez Orozco, 2011: 202) y que, por lo tanto, no solo deben vivir en el Ukhu Pacha sino que también buscan resarcirse ante Wirakocha. Sin embargo, quienes no tienen opción de redención son los partícipes de la violencia política, tanto senderistas como infantes de marina o ronderos. Recordemos si no ese coro de voces al que nos referimos más arriba: a todos ellos se les ha negado la salvación y es por eso que yacen inmovilizados en un pantano. De aquí se desprende un rasgo central para nuestra interpretación de este texto y que funciona a la vez como punto de contacto con $E l$ pez de oro en relación con el tránsito por este espacio de los muertos: la oportunidad de ser salvados se asienta en la capacidad para movilizarse de cada uno de los sujetos. Quienes se pasean sin ataduras son capaces de usufructuar, mediante ese libre tránsito, la salvación y el acceso al Hanan Pacha.

En el mundo de los vivos la resistencia andina en tanto que eje fundamental de la novela se manifiesta a través de la duda de Liborio con respecto a la ideología revolucionaria que impera entre sus compañeros de militancia. Así como el recorrido de Rosa por los tres espacios cosmológicos deja entrever un ostracismo destinado a los participantes de los enfrentamientos violentos entre los miembros del ejército y los de Sendero Luminoso, en los recorridos por el mundo de arriba por parte de su hijo se desprenden las razones de dicho desplazamiento. Ambos grupos abocados a la violencia política han optado por dejar de lado los saberes y creencias propias del mundo andino y, por lo tanto, han renunciado a la redención. Por dicha razón yacen empantanados en el Ukhu Pacha, sin posibilidad de moverse. A modo de ejemplo, en un pasaje de Rosa Cuchillo, Liborio discute acerca de la validez de las ideas políticas del Partido referidas al derrocamiento de un régimen capitalista en pos de la entronización de un plan de gobierno socialista, mientras agrega en claro desacuerdo que:

Lo deseable sería, piensas, un gobierno donde los naturales netos tengamos el poder de una vez por todas, sin ser sólo apoyo de otros. Ahí sí, caracho, te entusiasmas, volveríamos a bailar sin vergüenza nuestras propias danzas, en vez de esos bailes del extranjero, hablaríamos de nuevo el ruma simi, nuestro idioma propio, adoraríamos sin miedo de los curas a los dioses en los que tenemos creencia todavía. Sólo si así era la condición, valía la pena luchar, si no, ¿para qué pues? ¿Para que otros blancos sigan haciéndonos vivir como a ellos les gusta? (2005: 77)

La tesitura de lo expuesto por Liborio ofrece una clave de lectura que atraviesa todos los pasajes de la ficción en donde el hijo de Rosa participa de las acciones 
revolucionarias. A partir de ellas puede notarse claramente de qué manera los militantes senderistas son ajenos a esas creencias, dejando a Liborio en una posición que, por momentos y desde la visión de sus compañeros, roza la intransigencia. La caza de un animal y el consecuente enojo de los dioses de la montaña según el hijo de Rosa hacen que la razón eurocéntrica que organiza las formas de reflexionar del grupo de senderistas colisione con el imaginario mítico, aunque sin darle finalmente entidad: "En una de esas, clarito vieron en un resplandor que duró unos instantes, alzarse sobre un nevado difuminándose hacia el cielo, el espantoso rostro del tamaño de una montaña, de un hombre terrible, siniestro, que alargó sus tentáculos hacia el techo bajo el que se refugiaban", a lo que el personaje de Angicha responde: "Yo también pienso que esa aparición fue una ilusión óptica, efecto del resplandor del relámpago quizá, o acaso de las nubes" (2005: 122).

Como se observa, la ficción de Colchado expone su toma de posición con respecto a los saberes andinos. Deja en claro que, en ese enfrentamiento entre dos formas de racionalidad, la novela se inclina hacia la reivindicación de un imaginario arraigado fuertemente al territorio. Tanto en una como en otra de las travesías, la capacidad de ponerse en marcha tanto de Rosa como de Liborio funcionan como motores de la novela pero también como instancias de legitimación de una identidad andina capaz de preservar la diferencia ante las ideologías del "pensamiento misti" (2005: 77).

\section{Conclusiones}

En Rosa Cuchillo la doble articulación y las consecuentes resonancias entre las acciones de Rosa en su recorrido de ultratumba y las efectuadas por su hijo Liborio en el mundo de los vivos establecen un específico abordaje de la espacialidad andina. La muerte como momento fundador de una cultura es la significación fundamental que se desprende tanto de la ficción de Colchado como de Churata y, asimismo, el eslabón de sentido ausente en los esquemas de pensamiento provenientes de Occidente a los que se opone. La definición del propio territorio establece también, como vimos, una reformulación de las formas de abordar la Historia: la propuesta literaria de ambos autores tiene como objetivo principal redefinir el rol que asume la idea del tiempo homogéneo y vacío a través de las interrupciones y las discontinuidades que funcionan a nivel narratológico, ya que la escisión del relato en tanto que operación discursiva tiene como finalidad el cuestionamiento de los sucesos históricos.

En este sentido es que funciona la convergencia, en ambas textualidades, de la Historia con el discurso mítico. La lectura de los pormenores de la violencia entre el Estado y Sendero Luminoso en Rosa Cuchillo, así como la presencia del racismo y la expoliación inherente al gamonalismo en el capítulo "Puro andar" de El pez de oro, por poner sólo alguno de sus ejemplos, asumen la forma de mojones, establecen las líneas demarcatorias de una Historia con raíces latinoamericanas. Ambos proyectos escriturarios bosquejan un itinerario historiográfico oblicuo, despojado de naturalizaciones y representaciones adocenadas ya que exponen, al contrario, un método de lectura que se hace cargo de los detritus de la Historia. Se trata, en definitiva, de "leer lo que nunca fue escrito" como señala Walter Benjamin (2007: 126).

Pero si entonces este modelo de legibilidad se opone al principio hermenéutico corriente, lo buscado no consiste simplemente en una revancha de los oprimidos, de los olvidados de la Historia, de los que ya no están entre nosotros. Lo que se pretende es recuperar una reciprocidad factible al interior no de un sujeto individual sino de una multitud, un tumulto indistinguible del propio territorio en movimiento constante no hacia adelante sino en varias direcciones. Con nuestros muertos a cuestas. 


\section{Bibliografía}

» Aguiluz Ibarguen, Maya (2015). “Espacio para una mística de lo común. ¿Churata en perspectiva barroca?”. En Encrucijadas estético-políticas en el espacio andino (pp. 215-235). México: UNAM.

»Benjamin, Walter (2007). Sobre el concepto de historia. Tesis y fragmentos. Buenos Aires: Piedra de papel.

»Churata, Gamaliel (2011). El pez de oro. Lima: A.F.A.

»Churata, Gamaliel (2011b). "El pez de oro, o dialéctica del realismo psíquico, alfabeto del incognoscible". Conferencia dictada por el autor en el Cine Puno, el 30 de enero de 1965. Reproducida en El pez de oro. Lima: A.F.A.

»Churata, Gamaliel (2012). El pez de oro. Edición de Helena Usandizaga. Madrid: Cátedra.

» Colchado Lucio, Óscar (2005). Rosa Cuchillo. Lima: Editorial San Marcos.

"Cornejo Polar, Antonio (1982). “La novela indigenista: una desgarrada conciencia de la historia”. En Sobre literatura y crítica latinoamericanas (pp. 93-109). Caracas: Ediciones de la Facultad de Humanidades y Educación, Universidad Central de Venezuela.

»Cornejo Polar, Antonio (2008). “El mundo es ancho y ajeno y la obra de Ciro Alegría: Elementos para una interpretación”. En La novela peruana (pp. 45-75). Lima: CELACP.

»De Llano, Aymará (2009). No hay tal lugar. Literatura latinoamericana del siglo $X X$. Mar del Plata: EUDEM.

»De Llano, Aymará (2019). "Vivir será germinar: El pez de oro y la célula”. En Espezúa, Dorian y Salazar, Nécker (Eds.), Churata desde el sur (pp. 79-95). Lima: Pakarina.

»Di Benedetto, Matías (2019). "El pez de oro y el retorno de la vanguardia”. En Espezúa, Dorian y Salazar, Nécker (Eds.), Churata desde el sur (pp. 55-79). Lima: Pakarina.

"Flores Galindo, Alberto (1994). Buscando un inca. Identidad y utopía en los Andes. Lima: Horizonte.

» García Canclini, Néstor (2010). La sociedad sin relato. Antropología y estética de la inminencia. Buenos Aires: Katz.

» González Rosales, Dante (2002). El ichik ollko. Características de un ser fantástico. Alborada, no 25, pp. 24-30.

»Grüner, Eduardo (2010). La oscuridad y las luces. Capitalismo, cultura y revolución. Buenos Aires: Edhasa.

» López Maguiña, Santiago (2005). “Modos de racionalidad en Todas las sangres”. En Arguedas y el Perú de hoy (pp. 243-249). Lima: SUR.

»Lozada, Blitz (1995). “La concepción de las tres pachas en el imaginario aymara”. En Jornadas andinas de literatura latinoamericana 1993. La Paz: Plural.

» Moraña, Mabel (2015). Churata postcolonial. Lima: CELACP.

"Pérez Orozco, Edith (2011). Racionalidades en conflicto. Cosmovisión andino (y 
violencia política) en Rosa Cuchillo de Oscar Colchado. Lima: Pakarina.

»Ranciére, Jacques (2010). “El espectador emancipado”. En El espectador emancipado (pp. 9-29). Buenos Aires: Manantial.

"Rivera Cusicanqui, Silvia (2018). Un mundo chíxi es posible. Ensayos desde un presente en crisis. Buenos Aires: Tinta Limón.

»Steiner, George (2009). Extraterritorial. Ensayos sobre la literatura y la revolución del lenguaje. Buenos Aires: Adriana Hidalgo.

»Usandizaga, Helena (2005). Cosmovisión y conocimiento andino en El pez de oro de Churata. Revista Andina, $\mathrm{n}^{\circ}$ 40, primer semestre. Lima, Centro Bartolomé de Las Casas. 